\title{
Nanostructure Engineering of Metal-Organic Derived Frameworks: Cobalt Phosphide Embedded in Carbon Nanotubes as an Efficient ORR Catalyst
}

\author{
Syed Shoaib Ahmad Shah ${ }^{1,2} \mathbb{E}^{-}$, Tayyaba Najam ${ }^{3, *}$, Costas Molochas ${ }^{4}$, Muhammad Altaf Nazir ${ }^{2} \mathbb{D}$, \\ Angeliki Brouzgou ${ }^{5}\left(\mathbb{D}\right.$, Muhammad Sufyan Javed ${ }^{6}$, Aziz ur Rehman ${ }^{2, *}$ and Panagiotis Tsiakaras ${ }^{4,7,8, *(\mathbb{B})}$
}

1 Hefei National Laboratory for Physical Sciences at the Microscale, CAS Key Laboratory of Soft Matter Chemistry, Department of Chemistry, China University of Science and Technology, Hefei 230026, China; shoaib03ahmad@outlook.com

2 Institute of Chemistry, The Islamia University of Bahawalpur, Bahawalpur 63100, Pakistan; anch39@gmail.com

3 Institute for Advanced Study, Shenzhen University, Shenzhen 518060, China

4 Laboratory of Alternative Energy Conversion Systems, Department of Mechanical Engineering, School of Engineering, University of Thessaly, Pedion Areos, 38834 Athens, Greece; molospao@gmail.com

5 Department of Energy Systems, Faculty of Technology, University of Thessaly, Geopolis, 41500 Larissa, Greece; amprouzgou@uth.gr

check for updates

Citation: Shah, S.S.A.; Najam, T.; Molochas, C.; Nazir, M.A.; Brouzgou, A.; Javed, M.S.; Rehman, A.u.; Tsiakaras, P. Nanostructure Engineering of Metal-Organic Derived Frameworks: Cobalt Phosphide Embedded in Carbon Nanotubes as an Efficient ORR Catalyst. Molecules 2021, 26, 6672. https://doi.org/10.3390/ molecules 26216672

Academic Editors: Mihaela Baibarac, Monica Baia and Christos Riziotis

Received: 15 October 2021

Accepted: 1 November 2021

Published: 4 November 2021

Publisher's Note: MDPI stays neutral with regard to jurisdictional claims in published maps and institutional affiliations.

Copyright: (C) 2021 by the authors Licensee MDPI, Basel, Switzerland. This article is an open access article distributed under the terms and conditions of the Creative Commons Attribution (CC BY) license (https:/ / creativecommons.org/licenses/by/ $4.0 /)$.
6 School of Physical Science and Technology, Lanzhou University, Lanzhou 730000, China; muhammadsj@lzu.edu.cn

7 Laboratory of Materials and Devices for Clean Energy, Department of Technology of Electrochemical Processes, Ural Federal University, 19 Mira Str., 620002 Yekaterinburg, Russia

8 Laboratory of Electrochemical Devices Based on Solid Oxide Proton Electrolytes, Institute of High Temperature Electrochemistry, Russian Academy of Science (RAS), 620990 Yekaterinburg, Russia

* Correspondence: tayyabanajam@outlook.com (T.N.); azizypk@yahoo.com (A.u.R.); tsiak@uth.gr (P.T.)

\begin{abstract}
Heteroatom doping is considered an efficient strategy when tuning the electronic and structural modulation of catalysts to achieve improved performance towards renewable energy applications. Herein, we synthesized a series of carbon-based hierarchical nanostructures through the controlled pyrolysis of Co-MOF (metal organic framework) precursors followed by in situ phosphidation. Two kinds of catalysts were prepared: metal nanoparticles embedded in carbon nanotubes, and metal nanoparticles dispersed on the carbon surface. The results proved that the metal nanoparticles embedded in carbon nanotubes exhibit enhanced ORR electrocatalytic performance, owed to the enriched catalytic sites and the mass transfer facilitating channels provided by the hierarchical porous structure of the carbon nanotubes. Furthermore, the phosphidation of the metal nanoparticles embedded in carbon nanotubes (P-Co-CNTs) increases the surface area and porosity, resulting in faster electron transfer, greater conductivity, and lower charge transfer resistance towards ORR pathways. The P-Co-CNT catalyst shows a half-wave potential of $0.887 \mathrm{~V}$, a Tafel slope of $67 \mathrm{mV} \mathrm{dec}^{-1}$, and robust stability, which are comparatively better than the precious metal catalyst $(\mathrm{Pt} / \mathrm{C})$. Conclusively, this study delivers a novel path for designing multiple crystal phases with improved catalytic performance for energy devices.
\end{abstract}

Keywords: MOFs; nanostructure engineering; heteroatom doping; cobalt phosphide; oxygen reduction reaction

\section{Introduction}

Electrochemical energy conversion and storage technologies present great prospects due to their low environmental impact, high energy capacity, and excellent conversion efficiency, etc.; they include metal-air batteries, water electrolyzers, and fuel cells [1-3]. For metal-air batteries and fuel cells, the oxygen-reduction reaction (ORR) is considered 
a significant pathway [4-6]. Currently, platinum-based materials are the only available commercial electrocatalysts for efficiently accomplishing the ORR pathway due to their high catalytic performance and stability in alkaline and acidic environments [7-9]. However, platinum is an extremely expensive and scarce metal. Therefore, the development of alternative non-Pt ORR electrocatalysts is essential.

Recently, metal-organic frameworks (MOFs) have attracted extensive interest as novel porous materials [10]. MOFs present a larger surface area, easy functionalization, an enhanced structural diversity and better designability, compared to other traditional porous materials [11]. Additionally, by applying pyrolysis instead of other synthesis routes, MOFs with periodic crystalline structures and porosities can be obtained. This permits the integration of diverse functionalities in a single step as well as the specific control of shape, composition, size, and structure $[12,13]$. However, most of the synthesis methods used for preparing nanostructures from MOFs require morphology-preserved transformations and a templating strategy [14].

Heteroatom-doped MOF precursors can be utilized to synthesize co-doped nanomaterials, e.g., nitrogen-rich zeolitic imidazolate frameworks (ZIFs) [15,16]. This strategy facilitates host-guest interaction and produces more active sites due to geometric and electronic structure modulation. An alternative approach to preparing dual-doped nanomaterials is to introduce the heteroatom precursor into the MOF's pores [17,18]. For example, Co nanoparticles (NPs) encapsulated in porous carbon structures can be prepared by using $\mathrm{Zn-Co}$ MOFs precursors of optimized contents [19]. Furthermore, two MOFs in bimetallic ZIFs (ZIF-67 and ZIF-8) can yield porous carbon polyhedrons due to the high graphitization degree of Co-ZIF (ZIF-67) and the high surface area with more $\mathrm{N}$-atoms of Zn-ZIF (ZIF-8) [20-22]. However, pure ZIF-67 derived after pyrolysis usually leads to agglomerated Co NPs with irregular sizes; thus, it could not be considered a potential electrocatalyst for ORR.

MOF precursors are acknowledged as the best choice for synthesizing catalysts via temperature-programmed pyrolysis with tuned active sites. Additionally, MOF-derived $\mathrm{Co}_{2} \mathrm{P}$ NPs, by using hazardous P-source producing toxic fumes, are established as a bifunctional catalyst due to the formation of various active species, such as N, P co-doped carbon matrix, Co- $\mathrm{N}_{\mathrm{x}}$, and $\mathrm{Co}_{2} \mathrm{P}$ species [23]. However, the low electronic conductivity and mass transport of pure nanoparticles hinder the ORR performance. The challenge of fabricating nanomaterials with well-controlled structures and regulated physical, chemical, and electronic properties is still remained.

MOF-derived carbon nanotubes (CNTs) present particular features, such as high surface area, flexibility, and great mechanical strength, facilitating electron and ion transfer [24]. Typically, for the synthesis of 1D MOF-derived nanomaterials, two key approaches are utilized: self-templating and external templating strategies [25-28]. For example, Te@ZIF-8 was prepared by using an external template (ultrathin Te nanowire), followed by subsequent carbonization to produce hollow carbon nanofibers [29]. In other reports, the CNT growth was achieved by utilizing Fe and Ni metals [30,31]. Accordingly, composite materials doped with $\mathrm{Ni}, \mathrm{Co}$, or Fe can be self-templated during pyrolysis to fabricate in situ metal NPs with tubular nanostructures [32]. However, it is challenging to precisely control the dispersion and sites of heteroatoms in CNT-templated MOFs. Therefore, we highlight the urgency to develop facile and eco-friendly strategies for synthesizing MOFderived catalysts supported on in situ formed $\mathrm{Co}_{2} \mathrm{P}$, which can synergistically enhance the ORR performance.

Herein, we used an MOF-confined self-template strategy for the structural engineering of Co-coordinated carbon nanotubes and heteroatom-doped $\mathrm{Co}_{2} \mathrm{P}$ sites (P-Co-CNTs) by using phytic acid as an environmentally benign P-source (in contrast to previously reported hazardous P-sources, which cause $\mathrm{PH}_{3}$ generation [33-35]). Benefiting from the high surface area, the unique facet structure, synergistic effects, and enriched active species, the optimized P-Co-CNT catalyst showed more positive half-wave potential $\left(E_{1 / 2}=0.887 \mathrm{~V}\right.$ vs. RHE), a smaller Tafel slope $\left(67 \mathrm{mV} \mathrm{dec}^{-1}\right)$, and robust durability compared to the 
commercial Pt/C catalyst. The enhanced performance is attributed to the well-dispersed Co-phosphide active sites into the heteroatom-doped CNTs.

\section{Results and Discussion}

For the first time, we induced electronic structure modulations in Co-CNTs supported on $\mathrm{Co}_{2} \mathrm{P} / \mathrm{C}$ matrices. Our MOF-confined synthesis strategy provides highly stable active sites supported on an in situ-produced $\mathrm{Co}_{2} \mathrm{P} / \mathrm{C}$ porous support of high surface areas. Scheme 1 shows the fabrication of $\mathrm{Co}-\mathrm{CNTs}$ embedded in the surface of $\mathrm{Co}_{2} \mathrm{P} / \mathrm{C}$ porous support.
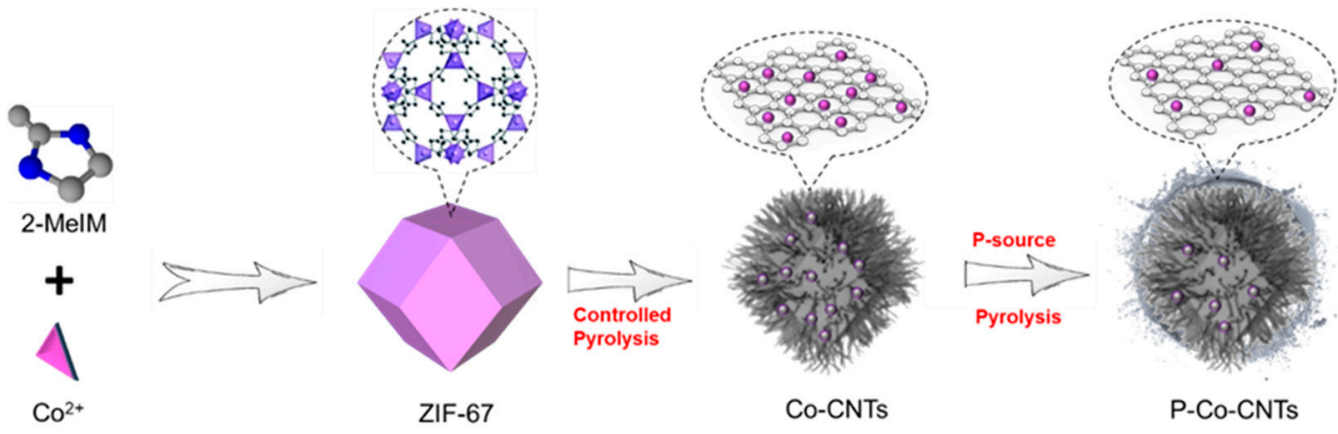

Scheme 1. Schematic representation of synthesis procedure for P-Co-CNTs nanostructure.

The synthesis strategy includes a two-stage carbonization process, which adjusts the electrocatalytic sites and modulates the electronic configuration of the active species during carbonization. During the first carbonization stage, the controlled-temperature pyrolysis leads to the evaporation of the organic linkers leaving $\mathrm{Co}^{2+}$ atoms, which steadily aggregate to form Co-CNTs on the NC surface. In the following step, phytic acid is used to remove the inactive species and the P-source, promoting the in situ growth of $\mathrm{Co}_{2} \mathrm{P} / \mathrm{C}$ porous/defective support during the second heating. For comparison reasons, catalysts without P-doping (Co-CNTs) and without CNTs growth (Co-NC) were also synthesized and tested.

The scanning electron microscopy images (SEM) confirm the typical morphology of ZIF-67, as shown in Figure 1a.

After the controlled programmed carbonization of $435 / 900{ }^{\circ} \mathrm{C}$, CNTs surrounding the polyhedron structures were formed, while the direct carbonization at $900{ }^{\circ} \mathrm{C}$ led to the formation of Co NPs over the NC surface (Figure 1b-d). Furthermore, the P-doping of Co-CNTs resulted in the absence of excessive Co NPs, possibly due to the formation of $\mathrm{Co}_{2} \mathrm{P}$ crystal phase in the NC (Figure 1e). Additionally, the porous morphology observed in the SEM image of P-Co-CNT sample indicates the triple role of Co-species as follows: (1) the formation of $\mathrm{Co}_{2} \mathrm{P}$ sites, (2) the prevention of Co agglomeration, and (3) the creation of porosity in the support.

Figure $1 \mathrm{f}$ shows the transmission electron microscopy (TEM) image of Co-CNTs, which clearly reveals the CNT surface embedded with small Co NPs, whereas the sample after P-doping confirms the absence of excessive Co NPs (Figure 1g,h).

The high-resolution TEM (HR-TEM) image (Figure 1i) further confirms the formation of $\mathrm{Co}_{2} \mathrm{P}$ NPs with a size of $5 \mathrm{~nm}$. Two types of lattice fringes, $\mathrm{Co}_{2} \mathrm{P}(121)$ and $\mathrm{CoN}_{\mathrm{x}}(211)$ planes, with interlayer spacings of $0.221 \mathrm{~nm}$ and $0.22 \mathrm{~nm}$, are observed in P-Co-CNTs. Moreover, as can be seen, the $\mathrm{Co}_{2} \mathrm{P}$ NPs are wrapped inside the graphitic shell, which can efficiently prevent NP corrosion or oxidation during harsh reaction conditions [36].

The combination of the scanning transmission electron microscopy and the energy dispersive spectroscopy (STEM-EDS) images (Figure 2a-e) confirms the existence of $C$, $\mathrm{N}, \mathrm{P}$, and Co. Additionally the perfect overlapping of $\mathrm{P}$ and Co distributions proves the existence of CoP moieties. 

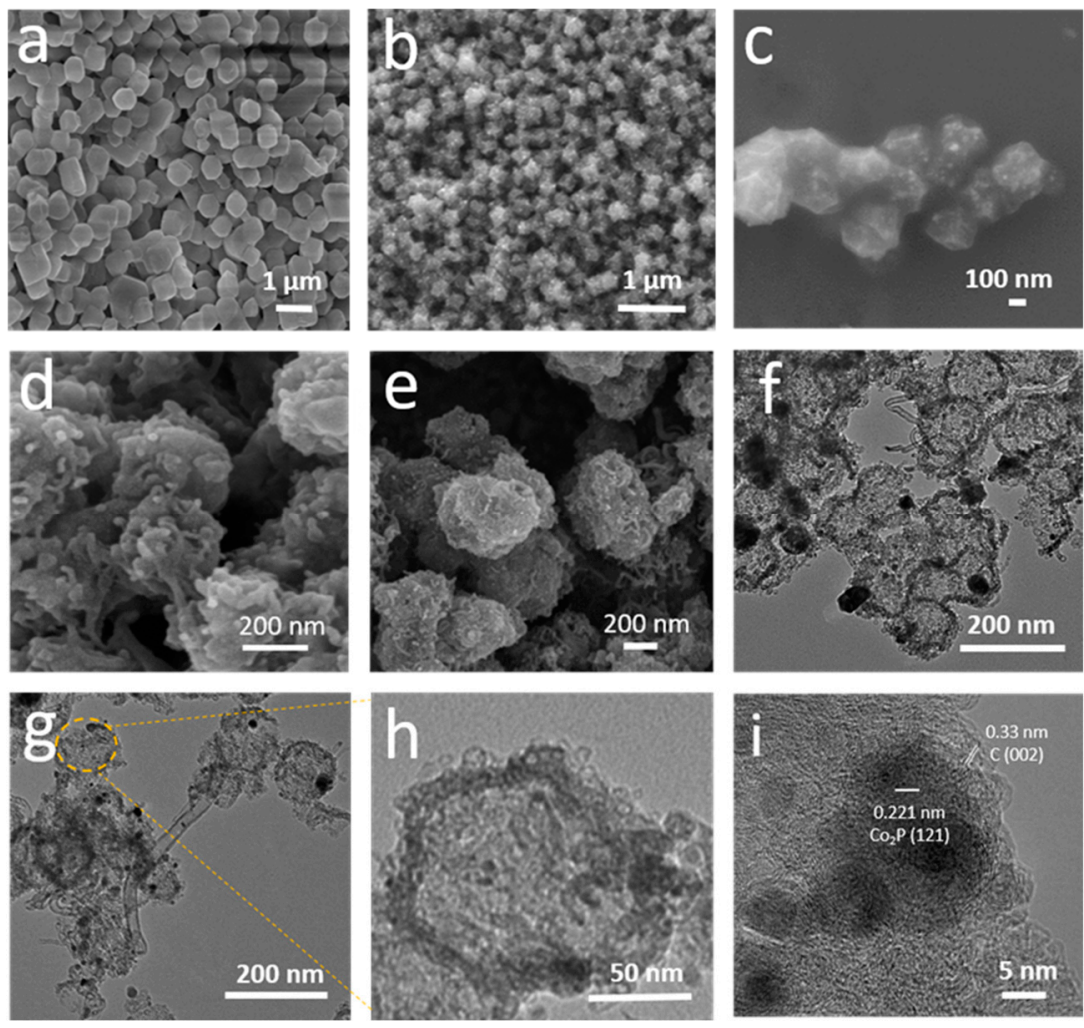

Figure 1. (a-e) SEM images of (a) ZIF-67; (b,c) Co-NC with high and low magnification, respectively; (d) Co-CNTs; (e) P-Co-CNTs; (f-h) TEM images of Co-CNTs and P-Co-CNTs, respectively; (i) HRTEM image of P-Co-CNTs.
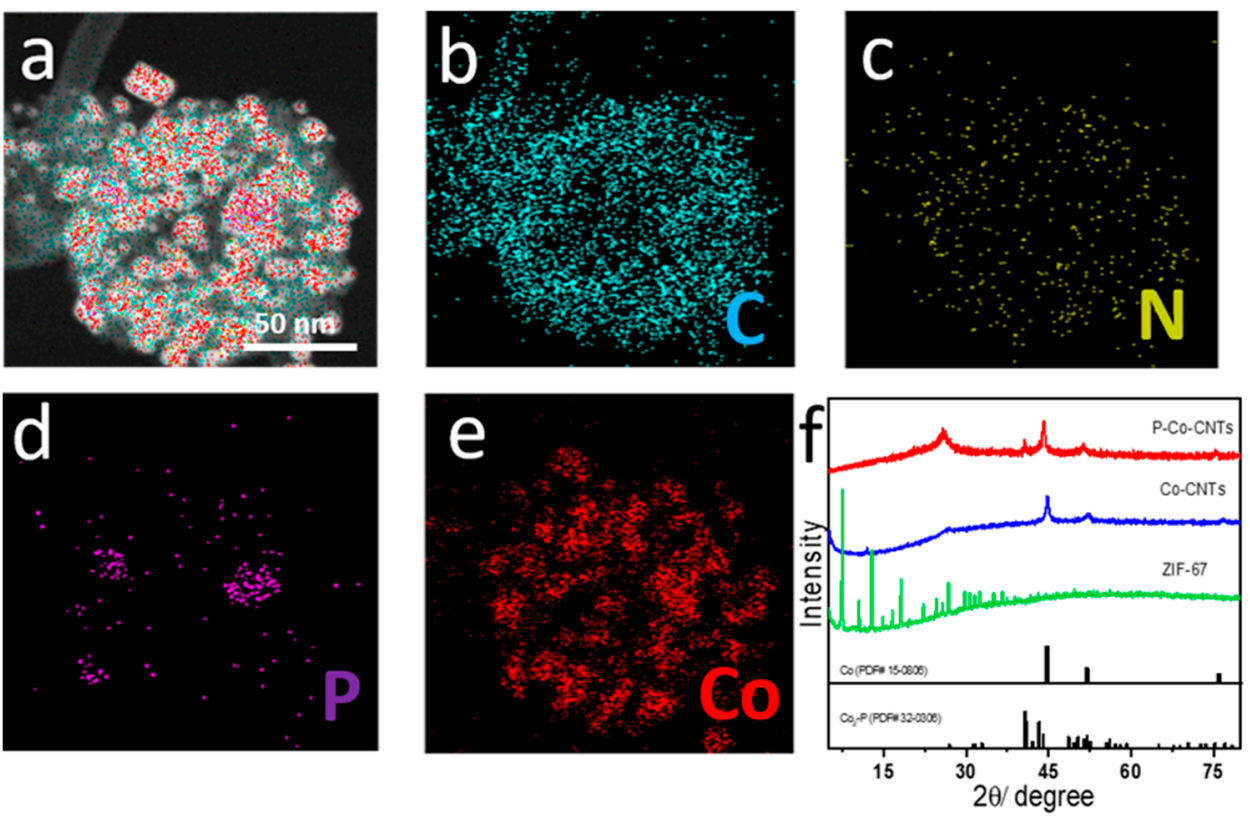

Figure 2. (a-e) STEM-EDS elemental mapping of P-Co-CNTs; (f) XRD patterns of ZIF-67, Co-CNTs, and P-Co-CNTs.

X-ray diffraction (XRD) patterns displayed in Figure $2 \mathrm{f}$ demonstrate the typical characteristic peaks of an MOF, confirming the formation of ZIF-67. The diffraction patterns of Co-CNTs and Co-NC samples (Figures 2 and S1) present peaks positioned at 44.3, 51.5, and $76^{\circ}$, consistent with the JCPDS \# 15-0806 for Co NPs, indicating their presence in the catalysts. 
Regarding the P-Co-CNT sample, it shows diffraction peaks located at 52.1, 43.3, 40.9, and $40.7^{\circ}$, corresponding to the (002), (211), (201), and (121) planes of $\mathrm{Co}_{2} \mathrm{P}$ (JCPDS \# 32-0306). The peaks at $74.98,50.7$, and $43.5^{\circ}$ correspond to the (220), (200), and (111) planes of Co$\mathrm{N}$, respectively (JCPDS \# 41-0943). Therefore, the existence of $\mathrm{Co}_{2} \mathrm{P}$ and Co- $\mathrm{N}$ planes in $\mathrm{P}-\mathrm{Co}-\mathrm{CNT}$ is confirmed.

Raman spectroscopy seen in Figure 3a, carried out to reveal the graphitization degree, shows a higher $I_{G} / I_{D}$ value for the P-Co-CNT than the Co-CNT sample. This result indicates a higher graphitization degree in P-Co-CNTs, which plays a crucial role in boosting the conductivity of the catalyst. The $\mathrm{N}_{2}$ adsorption-desorption isotherms displayed in Figure $3 b$ show a significantly higher BET surface area for P-Co-CNTs $\left(1123.6 \mathrm{~m}^{2} / \mathrm{g}\right)$ than for Co-CNTs $\left(979.1 \mathrm{~m}^{2} / \mathrm{g}\right)$. This fact indicates that the presence of $\mathrm{Co}_{2} \mathrm{P}$ species in $\mathrm{P}-\mathrm{Co}-\mathrm{CNTs}$ might successively provide adequate active moieties, accelerating the mass transfer during the ORR pathway.
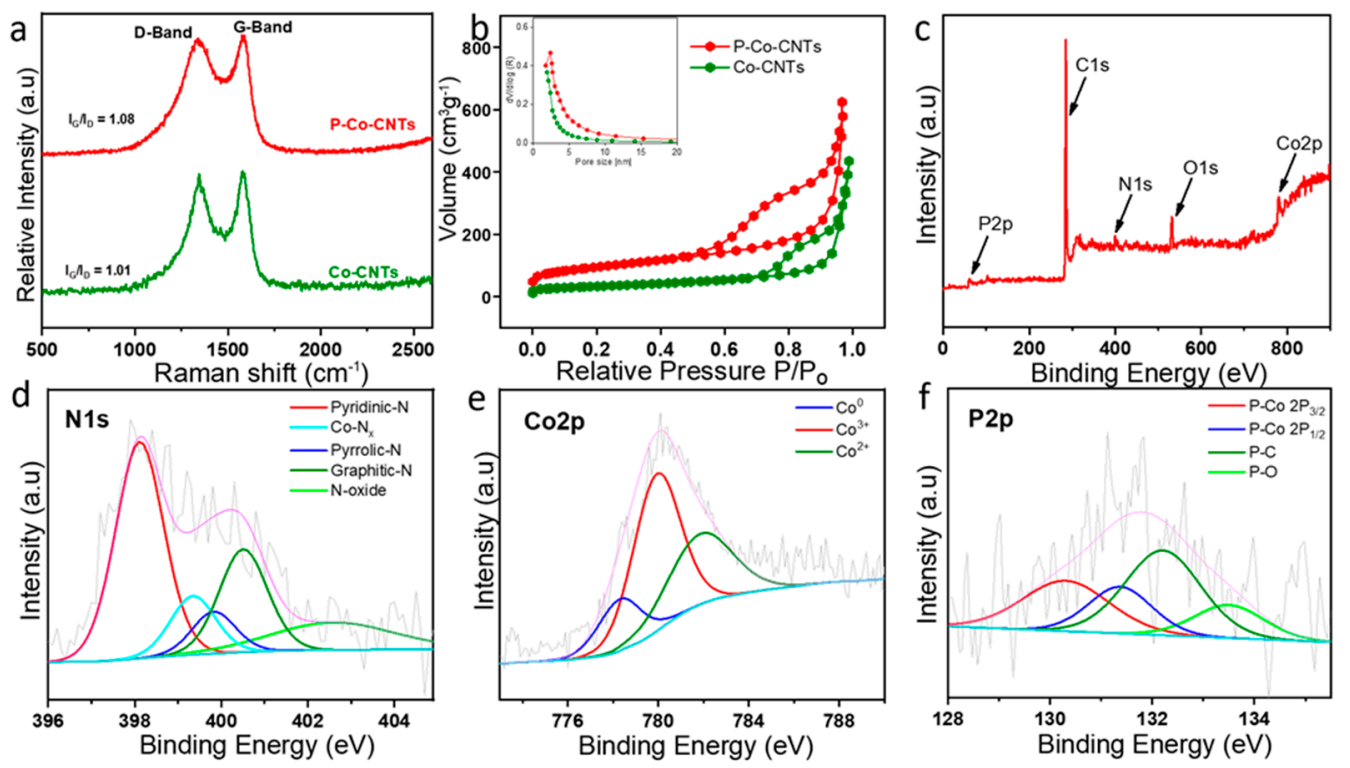

Figure 3. (a) Raman spectra of P-Co-CNTs and $\mathrm{Co}-\mathrm{CNTs}$ and (b) $\mathrm{N}_{2}$ adsorption-desorption isotherms (inset: pore-size distribution) of Co-CNTs and P-Co-CNTs; (c) XPS survey analysis of Co-CNTs; high-resolution XPS spectra of P-Co-CNTs; (d) N 1s; (e) Co 2p; (f) P 2p.

To further evaluate the surface features of the P-Co-CNT sample, $\mathrm{X}$-ray photoelectron spectroscopy (XPS) was carried out. The XPS survey revealed the existence of $\mathrm{C}, \mathrm{N}, \mathrm{O}$, $\mathrm{P}$, and Co elements (Figure 3c and Table S1, see Supplementary Materials). The N 1s spectra (Figure $3 \mathrm{~d}$ ) can be fitted into the representative peaks of five kinds of nitrogen, i.e., pyridinic-N, Co- $\mathrm{N}_{\mathrm{x}}$, pyrrolic-N, graphitic-N, and N-oxide, located at 398.1, 399.4, 399.9, 400.8 , and $402.7 \mathrm{eV}$, respectively. As shown in Figure 3e, the high-resolution Co $2 \mathrm{p}$ analysis displays three peaks for $\mathrm{Co}^{0}(778.4 \mathrm{eV}), \mathrm{Co}^{3+}(780 \mathrm{eV})$, and $\mathrm{Co}^{2+}(782.1 \mathrm{eV})$, representing the formation of a multifunctional active structure with three kinds of active species. The P $2 p$ spectrum is divided into two main peaks: $\mathrm{P}-\mathrm{O}$ and $\mathrm{P}-\mathrm{C}$ (Figure $3 \mathrm{f}$ ). The existence of the P-O peak demonstrates that the samples were exposed to surface oxidation. Notably, the spinorbit doublets peaks of $\mathrm{P} 2 \mathrm{p}_{3 / 2}$ and $\mathrm{P} 2 \mathrm{p}_{1 / 2}$ observed in the sample are attributed to the presence of the $\mathrm{P}-\mathrm{Co}$ bond. The $\mathrm{O}$ 1s spectrum is fitted in three peaks: $\mathrm{CoO}_{\mathrm{x}}, \mathrm{C}-\mathrm{O}-\mathrm{P} / \mathrm{C}-\mathrm{O}$, and $\mathrm{C}=\mathrm{O}$ (Figure S2, see Supplementary Materials). The $\mathrm{C}$ 1s spectrum displays the three kinds of peaks: C-O, C-N, and C-C peaks (Figure S3, see Supplementary Materials), confirming the successful $\mathrm{N}$-doping of the carbon matrix. Conclusively, all these results confirm the successful fabrication of P-Co-CNTs with homogeneously dispersed $\mathrm{Co}_{2} \mathrm{Co}_{2} \mathrm{P}$, and $\mathrm{Co}-\mathrm{N}_{\mathrm{x}}$ sites embedded in the carbon matrix.

The ORR activity of the as-synthesized catalysts was evaluated in the $\mathrm{O}_{2}$-saturated $0.1 \mathrm{M} \mathrm{KOH}$ electrolyte by cyclic voltammetry (CV) and linear sweep voltammetry (LSV) mea- 
surements on a ring disk electrode (RDE) (Figures 4a and S4). Additionally, Pt/C (20 wt. \%) was also tested for comparison. The $\mathrm{CV}$ curves reveal a more positive shift in the reduction peak along with greater current density by P-Co-CNTs as compared to Co-CNT catalyst in $\mathrm{O}_{2}$-saturated $0.1 \mathrm{M} \mathrm{KOH}$. This is attributed to the reduction in $\mathrm{O}_{2}$, since these peaks are absent in CVs conducted in $\mathrm{N}_{2}$-saturated solution (Figure S4, see Supplementary Materials). Figure 4a shows that the $\mathrm{P}-\mathrm{Co}-\mathrm{CNTs}$ exhibits superior performance, with a more positive half-wave potential $\left(E_{1 / 2}=0.887 \mathrm{~V}\right)$ than $\mathrm{Pt} / \mathrm{C}\left(E_{1 / 2}=0.858 \mathrm{~V}\right)$.
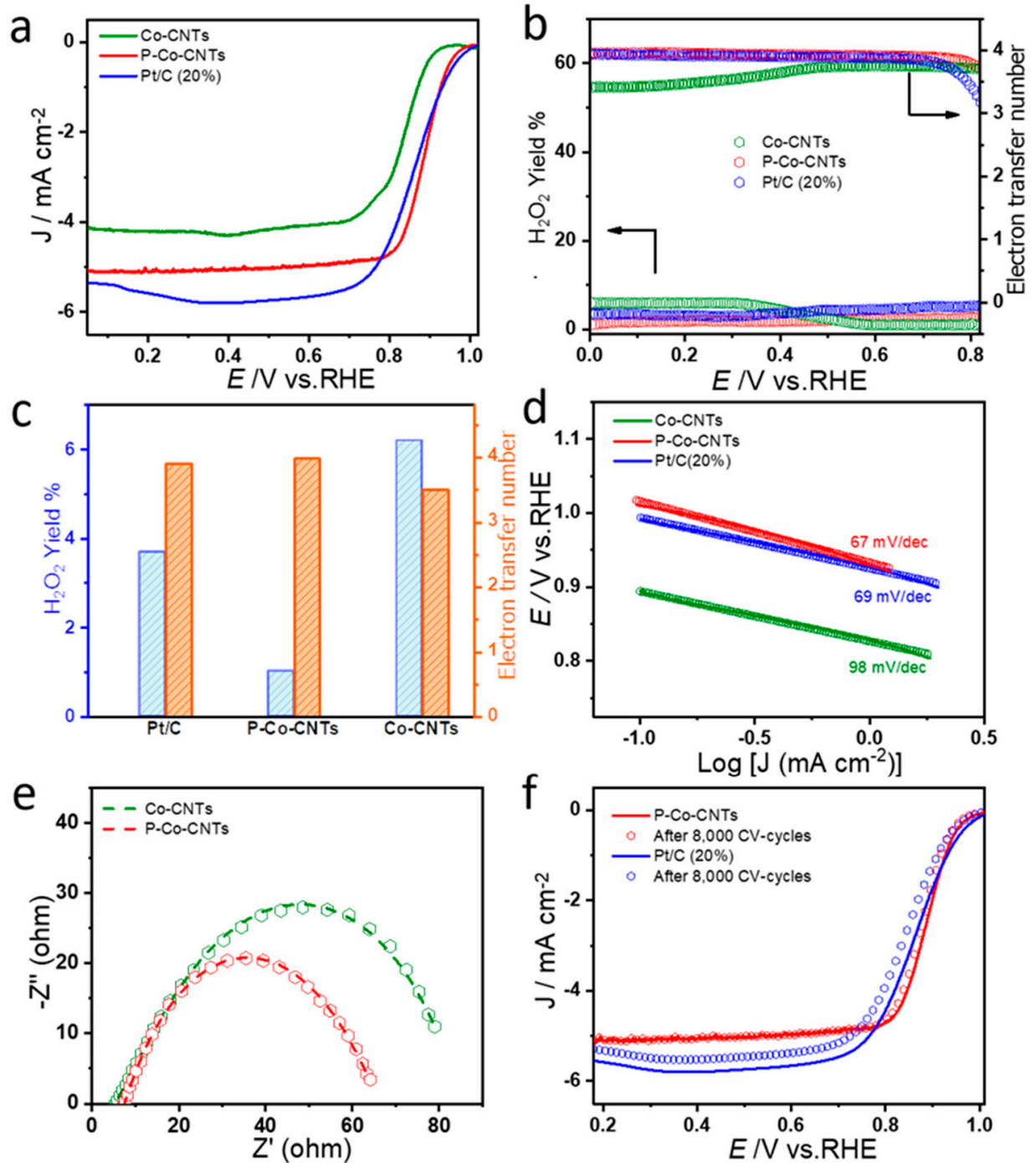

Figure 4. (a-d) ORR results for P-Co-CNTs, Co-CNTs, and Pt/C taken at $1600 \mathrm{rpm}$; (a) ORR LSV curves taken at $1600 \mathrm{rpm}$; (b) RRDE tests results taken at $1600 \mathrm{rpm}$; (c) peroxide production percentage and electron transfer number, and (d) Tafel slopes; (e) Nyquist plots from EIS for Co-CNTs, and P-Co-CNTs; (f) ORR LSV curves before and after stability tests for P-Co-CNTs and Pt/C.

Notably, an inferior ORR activity was revealed by the un-doped Co-based catalyst (Co-CNTs) with an $E_{1 / 2}$ difference of $71 \mathrm{mV}$, compared to P-Co-CNTs, thus signifying that after P-doping, the new active species formed improves the intrinsic ORR performance by altering the electronic structure.

Rotating ring disk electrode (RRDE) tests were conducted to monitor the ORR pathway at $1600 \mathrm{rpm}$. The electron transfer number for P-Co-CNTs calculated from the RRDE data is around 3.9, indicating a $4 \mathrm{e}^{-}$pathway, thus efficiently catalyzing the oxygen reduction into water (Figure $4 \mathrm{~b}, \mathrm{c})$. The lowest percentage of peroxide production $(1.02 \%)$ 
is exhibited by $\mathrm{P}-\mathrm{Co}-\mathrm{CNTs}$, whereas $\mathrm{Pt} / \mathrm{C}$ and $\mathrm{Co}-\mathrm{CNT}$ catalysts show slightly higher peroxide productions, about $3.7 \%$ and $6.2 \%$, respectively (Figure $4 \mathrm{~b}, \mathrm{c}$ ).

The high activity of the P-Co-CNT catalyst is attributed to the high surface areas, the unique facet structures, the superior conductivity, or even to the imprecise synergistic effect of active species. The Tafel slopes were further calculated to evaluate the ORR kinetics (Figure 4d). The superior ORR performance of the P-Co-CNTs becomes apparent from its lower Tafel slope $\left(67 \mathrm{mV} \mathrm{dec}^{-1}\right)$ compared to Co-CNTs $\left(98 \mathrm{mV} \mathrm{dec}^{-1}\right)$ and $\mathrm{Pt} / \mathrm{C}\left(69 \mathrm{mV} \mathrm{dec}^{-1}\right)$. In order to monitor the role of CNTs towards ORR activity, the performance of a sample fabricated without CNT growth (Co-NC) was investigated. Figure S5 shows that the Co-NC catalyst exhibits an $E_{1 / 2}$ negative shift of $67 \mathrm{mV}$ as compared to the $\mathrm{Co}-\mathrm{CNT}$ catalyst, indicating that the improved ORR activity is due to the vertical growth of CNTs on the NC surface. The electrochemical impedance spectroscopy (EIS) (Figure 4e) demonstrates the lowermost polarization (charge-transfer and mass-transfer) resistance for P-Co-CNTs compared with the un-doped catalyst, due to the well-defined channels (CNTs) and the P-doping that can form new active species, improving the intrinsic ORR performance by altering the electronic structure.

Since the stability of the catalysts is crucial for real-world utilization, we investigated the stability of the as-synthesized catalysts at a sweep rate of $50 \mathrm{mV} \mathrm{s}^{-1}$ for $8000 \mathrm{CV}$-cycles in $\mathrm{O}_{2}$-saturated $0.1 \mathrm{M} \mathrm{KOH}$ solution. Figure $4 \mathrm{f}$ shows that the P-Co-CNTs electrocatalyst exhibits strong long-term stability, while almost retaining its initial activity, by showing a minimum loss in $E_{1 / 2}$ of $2 \mathrm{mV}$. On the contrary, the Pt/C catalyst shows a higher activity decay of $10 \mathrm{mV}$ in $E_{1 / 2}$. In conclusion, we confirmed that P-Co-CNT is a promising ORR electrocatalyst with respect to other reported catalysts (Table S2, see Supplementary Materials).

Based on the above findings, we summarized that the structural changes occurring through P-doping promote the formation of $\mathrm{Co}_{2} \mathrm{P}$ species. Phosphorous has a higher electron donation ability, larger atomic radius, and similar chemical properties with respect to nitrogen. Nitrogen can induce a net positive charge on carbon atoms due to the difference between their electronegativity values [37]. Correspondingly, P-doping may facilitate the ORR process by positively inducing charge to the carbon atoms, promoting the attraction of electrons and the effective breaking of the $\mathrm{O}-\mathrm{O}$ bonding [38-41]. In addition, we confirmed the crucial role of CNTs on the improved ORR activity by demonstrating a lower ORR activity for a catalyst synthesized without CNTs growth (Figure S5, see Supplementary Materials) [21]. In conclusion, the superior ORR catalytic activity of P-Co-CNTs is attributed to the synergistic effect between the single Co-CNTs, $\mathrm{Co}_{2} \mathrm{P}$ species, and the $\mathrm{P}$ - and $\mathrm{N}$-doped carbon matrix.

\section{Materials and Methods}

\subsection{Materials}

Cobalt nitrate hexahydrate, 2-methyl imidazole, phytic acid, and methanol were purchased from Aladdin supplier with $99.9 \%$ purity.

\subsection{Catalyst Preparation}

3.2.1. Synthesis of ZIF-67

Solution A was prepared by homogeneously dissolving $\mathrm{Co}\left(\mathrm{NO}_{3}\right)_{2} \cdot 6 \mathrm{H}_{2} \mathrm{O}(3 \mathrm{~g})$ in methanol $(60 \mathrm{~mL})$. Then, Solution B, containing $45 \mathrm{mmol}$ of 2-methylimidazole (2-MeIM) and dispersed in $60 \mathrm{~mL}$ of methanol, was mixed with solution A and continuously stirred for $24 \mathrm{~h}$. The final product was collected by centrifugation and washed several times with methanol.

\subsubsection{Synthesis of $\mathrm{Co}-\mathrm{CN}$}

A sample of $0.5 \mathrm{~g}$ of ZIF-67 was placed in a ceramic boat and carbonized at $900{ }^{\circ} \mathrm{C}$ under $\mathrm{Ar} / \mathrm{H}_{2}$ (95:5) environment at $5{ }^{\circ} \mathrm{C} / \mathrm{min}$ for $3 \mathrm{~h}$. 


\subsubsection{Synthesis of Co-CNTs}

The as-obtained ZIF-67 sample was carbonized, firstly at $435{ }^{\circ} \mathrm{C}$ for $1 \mathrm{~h}$ under an $\mathrm{Ar} / \mathrm{H}_{2}$ (95:5) environment with a rate of $3^{\circ} \mathrm{C} \mathrm{min}^{-1}$, and secondly, the temperature further increased to $900{ }^{\circ} \mathrm{C}$ for $3 \mathrm{~h}$ with $5^{\circ} \mathrm{C} \mathrm{min}^{-1}$.

\subsubsection{Synthesis of P-Co-CNTs}

Phytic acid $(4 \mathrm{~mL})$ was added into $20 \mathrm{~mL}$ of ethanol containing homogeneously dispersed Co-CNTs (100 mg), followed by $12 \mathrm{~h}$ of stirring. Then, the final product was collected after washing with deionized water and dried in an oven. The final sample was obtained after carbonization under an $\mathrm{Ar} / \mathrm{H}_{2}$ (95:5) environment with $5{ }^{\circ} \mathrm{C} \mathrm{min}{ }^{-1}$ at $900{ }^{\circ} \mathrm{C}$ for $1 \mathrm{~h}$.

\subsection{Physicochemical Characterization}

The morphology of the as-synthesized samples was monitored by SEM, TEM, HRTEM and STEM-EDS. The scanning electron microscopy (SEM) images were recorded on JSM-7800F (JEOL) at an accelerated voltage of $15 \mathrm{kV}$. The transmission electron microscopy (TEM), high-resolution TEM (HR-TEM), and EDS (energy dispersive spectroscopy) images were observed on Tecnai G2F20S-TWIN at an accelerated voltage of $200 \mathrm{kV}$. Furthermore, the crystal structure of the samples was monitored by X-ray diffraction (XRD, Shimadzu $X$-ray diffractometer) at a scan rate of $5{ }^{\circ} \mathrm{C} \mathrm{min}^{-1}$. The $\mathrm{N}_{2}$ adsorption-desorption isotherms were collected on Kubo X1000 sorption analyzer instrument at $77 \mathrm{~K}$, and specific surface areas were estimated by the Brunauer-Emmett-Teller (BET) method. Raman spectroscopy was carried out on LabRamHR evolution spectrometer operated at $532 \mathrm{~nm}$, equipped with a $\mathrm{Nb}$-Yag laser excitation source. The elemental composition and valence states were studied by X-ray photoelectron spectroscopy (XPS, ESCALAB250Xi spectrometer).

\subsection{Electrochemical Characterization}

The Autolab electrochemical workstation was used to carry out all the ORR tests. The electrochemical measurements were conducted in a three-electrode system, consisting of a working electrode (a glassy carbon rotating disk), a counter electrode (a graphitic carbon rod), and a reference electrode (vs. $\mathrm{Ag} / \mathrm{AgCl}$ ). The recorded working potentials vs. $\mathrm{Ag} \mid \mathrm{AgCl}(3 \mathrm{M} \mathrm{KCl})$ were converted into the reversible hydrogen electrode (RHE) according to the equation $\mathrm{E}(\mathrm{RHE})=\mathrm{E}(\mathrm{Ag} \mid \mathrm{AgCl})+0.059 \mathrm{pH}+0.210 \mathrm{~V}$, where $\mathrm{pH}(0.1 \mathrm{M} \mathrm{KCl})=5.8$ [42]. A catalyst loading of $0.3 \mathrm{mg} \mathrm{cm}^{-2}$ was deposited on the glassy carbon electrode surface $\left(0.19625 \mathrm{~cm}^{2}\right)$. Cyclic voltammetry $(\mathrm{CV})$ and linear sweep voltammetry (LSV) curves were taken in $\mathrm{O}_{2}$-saturated (or $\mathrm{N}_{2}$-saturated) $0.1 \mathrm{M} \mathrm{KOH}$ solution at sweep rates of $50 \mathrm{mV} \mathrm{s}^{-1}$ and $10 \mathrm{mV} \mathrm{s}^{-1}$, respectively.

The rotating ring disk electrode (RRDE) experiments for the ORR pathway study were performed in $\mathrm{O}_{2}$-saturated solution in a standard three-electrode cell at room temperature. The total electron-transfer number $(n)$ and the hydrogen peroxide yield $\left(\% \mathrm{H}_{2} \mathrm{O}_{2}\right)$ were determined from RRDE tests, as seen below:

$$
\begin{gathered}
n=\frac{4 \times I_{D}}{I_{D}+\frac{I_{R}}{N}} \\
\% \text { Hydrogen peroxide }=\left(\frac{I_{D}+\frac{I_{R}}{N}}{I_{D}+\frac{I_{R}}{N}}\right) \times 100
\end{gathered}
$$

where $N(=0.37)$ is the $\mathrm{H}_{2} \mathrm{O}_{2}$ collection efficiency of the Pt ring, $I_{D}$ is the disk current, and $I_{R}$ is the ring current.

Electrochemical impedance spectroscopy was carried out at $0.8 \mathrm{~V}$ vs. RHE for ORR within the frequency range of $10^{5}$ and $0.01 \mathrm{~Hz}$ and an AC potential amplitude of $10 \mathrm{mV}$. 


\section{Conclusions}

In summary, the successful fabrication of the $\mathrm{Co}-\mathrm{CNTs}$ and $\mathrm{Co}_{2} \mathrm{P}$ embedded in an $\mathrm{N}$-doped carbon matrix was achieved via a structural modulation strategy. The heteroatomdoped nanostructured porous carbon materials with high surface areas, permanent and uniform porosity, and well-regulated functionalities were attained, which would be difficult using conventional methods. The optimized P-Co-CNT catalyst showed a higher $E_{1 / 2}$ of $0.887 \mathrm{~V}$ vs. RHE compared to Co-CNTs and Pt/C (20 wt. \%) catalysts. These findings showed that the heteroatom doping of $\mathrm{Co}-\mathrm{CNTs}$ in the carbon framework generates charge redistribution and synergistic effects, resulting in improved catalytic performance. Hence, this strategy paves a new route for improving heterogeneous catalysis toward energy applications.

Supplementary Materials: The following are available online, Figure S1: XRD pattern of Co-NC; Figure S2: High-resolution O1s XPS analysis of P-Co-CNTs; Figure S3: High-resolution C1s XPS analysis of P-Co-CNTs; Figure S4: CV curves conducted under $\mathrm{N}_{2}$ and $\mathrm{O}_{2}$ saturated $0.1 \mathrm{M} \mathrm{KOH}$ solution: (a) Co-CNTs and (b) P-Co-CNTs; Figure S5: ORR-LSV curves conducted under $\mathrm{O}_{2}$ saturated $0.1 \mathrm{M} \mathrm{KOH}$ solution; Table S1: Elemental contents of P-Co-CNTs determined by XPS spectra; Table S2: Comparative study of ORR performance of the as-synthesized catalyst with reported catalysts under $0.1 \mathrm{M} \mathrm{KOH}$ solution vs. RHE.

Author Contributions: Methodology, validation, formal analysis, and investigation, S.S.A.S., C.M. and M.A.N.; writing original draft preparation and data curation, A.B. and M.S.J.; conceptualization, supervision, resources, and writing-review and editing T.N., A.u.R. and P.T. All authors have read and agreed to the published version of the manuscript.

Funding: This research received no external funding.

Institutional Review Board Statement: Not applicable.

Informed Consent Statement: Not applicable.

Data Availability Statement: The data presented in this study are available on request from the corresponding authors.

Acknowledgments: S.S.A. Shah is grateful to the higher education commission (HEC) of Pakistan for IPFP funding at the Institute of Chemistry, The Islamia University of Bahawalpur, Pakistan. Furthermore, P. Tsiakaras, A. Brouzgou and C. Molochas thankfully acknowledge the co-financing by the European Union \& Greek National funds through the Operational Program Competitiveness, Entrepreneurship, and Innovation, under the call RESEARCH-CREATE-INNOVATE (T1EDK-02442).

Conflicts of Interest: The authors declare no conflict of interest.

Sample Availability: Samples of the compounds are not available from the authors.

\section{References}

1. Shah, S.S.A.; Najam, T.; Wen, M.; Zang, S.-Q.; Waseem, A.; Jiang, H.-L. Metal-Organic Framework-based Electrocatalysts for $\mathrm{CO}_{2}$ Reduction. Small Struct. 2021, 2100090. [CrossRef]

2. Gawande, M.B.; Goswami, A.; Asefa, T.; Guo, H.; Biradar, A.V.; Peng, D.-L.; Zboril, R.; Varma, R.S. Core-shell nanoparticles: Synthesis and applications in catalysis and electrocatalysis. Chem. Soc. Rev. 2015, 44, 7540-7590. [CrossRef] [PubMed]

3. Jing, S.; Zhang, L.; Luo, L.; Lu, J.; Yin, S.; Shen, P.K.; Tsiakaras, P. N-Doped Porous Molybdenum Carbide Nanobelts as Efficient Catalysts for Hydrogen Evolution Reaction. Appl. Catal. B Environ. 2018, 224, 533-540. [CrossRef]

4. Duan, J.; Chen, S.; Jaroniec, M.; Qiao, S.Z. Heteroatom-Doped Graphene-Based Materials for Energy-Relevant Electrocatalytic Processes. ACS Catal. 2015, 5, 5207-5234. [CrossRef]

5. Tzorbatzoglou, F.; Brouzgou, A.; Tsiakaras, P. Electrocatalytic activity of Vulcan-XC-72 supported Pd, Rh and PdxRhy toward HOR and ORR. Appl. Catal. B Environ. 2015, 174-175, 203-211. [CrossRef]

6. Najam, T.; Ahmad Shah, S.S.; Ali, H.; Song, Z.; Sun, H.; Peng, Z.; Cai, X. A metal free electrocatalyst for high-performance zinc-air battery application with good resistance towards poisoning species. Carbon 2020, 164, 12-18. [CrossRef]

7. Colic, V.; Bandarenka, A.S. Pt Alloy Electrocatalysts for the Oxygen Reduction Reaction: From Model Surfaces to Nanostructured Systems. ACS Catal. 2016, 6, 5378-5385. [CrossRef]

8. Wu, R.; Tsiakaras, P.; Shen, P.K. Facile synthesis of bimetallic Pt-Pd symmetry-broken concave nanocubes and their enhanced activity toward oxygen reduction reaction. Appl. Catal. B Environ. 2019, 251, 49-56. [CrossRef] 
9. Long, G.-F.; Li, X.-H.; Wan, K.; Liang, Z.-X.; Piao, J.-H.; Tsiakaras, P. Pt/CN-doped electrocatalysts: Superior electrocatalytic activity for methanol oxidation reaction and mechanistic insight into interfacial enhancement. Appl. Catal. B Environ. 2017, 203, 541-548. [CrossRef]

10. Shah, S.S.A.; Najam, T.; Aslam, M.K.; Ashfaq, M.; Rahman, M.M.; Wang, K.; Tsiakaras, P.; Song, S.; Wang, Y. Recent advances on oxygen reduction electrocatalysis: Correlating the characteristic properties of metal organic frameworks and the derived nanomaterials. Appl. Catal. B Environ. 2020, 268, 118570. [CrossRef]

11. Li, Y.; Karimi, M.; Gong, Y.-N.; Dai, N.; Safarifard, V.; Jiang, H.-L. Integration of metal-organic frameworks and covalent organic frameworks: Design, synthesis, and applications. Matter 2021, 4, 2230-2265. [CrossRef]

12. Shah, S.S.A.; Najam, T.; Rahman, M.M. Metal-organic framework-derived catalysts for Zn-Air batteries. In Handbook of Nanomaterials and Nanocomposites for Energy and Environmental Applications; Kharissova, O.V., Martínez, L.M.T., Kharisov, B.I., Eds.; Springer International Publishing: Cham, Switzerland, 2020; pp. 1-15.

13. Aslam, M.K.; Shah, S.S.A.; Li, S.; Chen, C. Kinetically controlled synthesis of MOF nanostructures: Single-holed hollow core-shell ZnCoS@Co9S8/NC for ultra-high performance lithium-ion batteries. J. Mater. Chem. A 2018, 6, 14083-14090. [CrossRef]

14. Zhang, W.; Cai, G.; Wu, R.; He, Z.; Yao, H.-B.; Jiang, H.-L.; Yu, S.-H. Templating Synthesis of Metal-Organic Framework Nanofiber Aerogels and Their Derived Hollow Porous Carbon Nanofibers for Energy Storage and Conversion. Small 2021, 2004140. [CrossRef]

15. Sun, K.; Liu, M.; Pei, J.; Li, D.; Ding, C.; Wu, K.; Jiang, H.-L. Incorporating Transition-Metal Phosphides into Metal-Organic Frameworks for Enhanced Photocatalysis. Angew. Chem. Int. Ed. 2020, 59, 22749-22755. [CrossRef] [PubMed]

16. Shah, S.S.A.; Najam, T.; Javed, M.S.; Rahman, M.M.; Tsiakaras, P. Novel Mn-/Co-Nx Moieties Captured in N-Doped Carbon Nanotubes for Enhanced Oxygen Reduction Activity and Stability in Acidic and Alkaline Media. ACS Appl. Mater. Interfaces 2021, 13, 23191-23200. [CrossRef] [PubMed]

17. Xia, W.; Mahmood, A.; Zou, R.; Xu, Q. Metal-organic frameworks and their derived nanostructures for electrochemical energy storage and conversion. Energy Environ. Sci. 2015, 8, 1837-1866. [CrossRef]

18. Najam, T.; Shah, S.S.A.; Ding, W.; Wei, Z. Role of P-doping in Antipoisoning: Efficient MOF-Derived 3D Hierarchical Architectures for the Oxygen Reduction Reaction. J. Phys. Chem. C 2019, 123, 16796-16803. [CrossRef]

19. Chen, Y.-Z.; Wang, C.; Wu, Z.-Y.; Xiong, Y.; Xu, Q.; Yu, S.-H.; Jiang, H.-L. From Bimetallic Metal-Organic Framework to Porous Carbon: High Surface Area and Multicomponent Active Dopants for Excellent Electrocatalysis. Adv. Mater. 2015, 27, 5010-5016. [CrossRef] [PubMed]

20. You, B.; Jiang, N.; Sheng, M.; Drisdell, W.S.; Yano, J.; Sun, Y. Bimetal-Organic Framework Self-Adjusted Synthesis of Support-Free Nonprecious Electrocatalysts for Efficient Oxygen Reduction. ACS Catal. 2015, 5, 7068-7076. [CrossRef]

21. Shah, S.S.A.; Peng, L.S.; Najam, T.; Cheng, C.; Wu, G.P.; Nie, Y.; Ding, W.; Qi, X.Q.; Chen, S.G.; Wei, Z.D. Monodispersed Co in Mesoporous Polyhedrons: Fine-tuning of ZIF-8 Structure with Enhanced Oxygen Reduction Activity. Electrochim. Acta 2017, 251, 498-504. [CrossRef]

22. Wu, X.; Meng, G.; Liu, W.; Li, T.; Yang, Q.; Sun, X.; Liu, J. Metal-organic framework-derived, Zn-doped porous carbon polyhedra with enhanced activity as bifunctional catalysts for rechargeable zinc-air batteries. Nano Res. 2018, 11, 163-173. [CrossRef]

23. Indra, A.; Song, T.; Paik, U. Metal Organic Framework Derived Materials: Progress and Prospects for the Energy Conversion and Storage. Adv. Mater. 2018, 30, 1705146. [CrossRef] [PubMed]

24. Zhang, L.; Wang, X.; Wang, R.; Hong, M. Structural Evolution from Metal-Organic Framework to Hybrids of Nitrogen-Doped Porous Carbon and Carbon Nanotubes for Enhanced Oxygen Reduction Activity. Chem. Mater. 2015, 27, 7610-7618. [CrossRef]

25. Pachfule, P.; Shinde, D.; Majumder, M.; Xu, Q. Fabrication of carbon nanorods and graphene nanoribbons from a metal-organic framework. Nat. Chem. 2016, 8, 718-724. [CrossRef]

26. Lee, H.J.; Cho, W.; Lim, E.; Oh, M. One-pot synthesis of magnetic particle-embedded porous carbon composites from metal-organic frameworks and their sorption properties. Chem. Commun. 2014, 50, 5476-5479. [CrossRef]

27. Zheng, F.; Xia, G.; Yang, Y.; Chen, Q. MOF-derived ultrafine MnO nanocrystals embedded in a porous carbon matrix as high-performance anodes for lithium-ion batteries. Nanoscale 2015, 7, 9637-9645. [CrossRef]

28. Shah, S.S.A.; Najam, T.; Cheng, C.; Peng, L.; Xiang, R.; Zhang, L.; Deng, J.; Ding, W.; Wei, Z. Exploring Fe-Nx for Peroxide Reduction: Template-Free Synthesis of Fe-Nx Traumatized Mesoporous Carbon Nanotubes as an ORR Catalyst in Acidic and Alkaline Solutions. Chem. Eur. J. 2018, 24, 10630-10635. [CrossRef] [PubMed]

29. Zhang, W.; Wu, Z.-Y.; Jiang, H.-L.; Yu, S.-H. Nanowire-Directed Templating Synthesis of Metal-Organic Framework Nanofibers and Their Derived Porous Doped Carbon Nanofibers for Enhanced Electrocatalysis. J. Am. Chem. Soc. 2014, 136, 14385-14388. [CrossRef] [PubMed]

30. Liu, T.; Zhao, P.; Hua, X.; Luo, W.; Chen, S.; Cheng, G. An Fe-N-C hybrid electrocatalyst derived from a bimetal-organic framework for efficient oxygen reduction. J. Mater. Chem. A 2016, 4, 11357-11364. [CrossRef]

31. Chen, L.; Bai, J.; Wang, C.; Pan, Y.; Scheer, M.; You, X. One-step solid-state thermolysis of a metal-organic framework: A simple and facile route to large-scale of multiwalled carbon nanotubes. Chem. Commun. 2008, 13, 1581-1583. [CrossRef] [PubMed]

32. Barman, B.K.; Nanda, K.K. Prussian blue as a single precursor for synthesis of Fe/Fe3C encapsulated N-doped graphitic nanostructures as bi-functional catalysts. Green Chem. 2016, 18, 427-432. [CrossRef]

33. Li, D.; Senevirathne, K.; Aquilina, L.; Brock, S.L. Effect of Synthetic Levers on Nickel Phosphide Nanoparticle Formation: Ni5P4 and NiP2. Inorg. Chem. 2015, 54, 7968-7975. [CrossRef] [PubMed] 
34. Habas, S.E.; Baddour, F.G.; Ruddy, D.A.; Nash, C.P.; Wang, J.; Pan, M.; Hensley, J.E.; Schaidle, J.A. A Facile Molecular Precursor Route to Metal Phosphide Nanoparticles and Their Evaluation as Hydrodeoxygenation Catalysts. Chem. Mater. 2015, 27, 7580-7592. [CrossRef]

35. Zhong, X.; Jiang, Y.; Chen, X.; Wang, L.; Zhuang, G.; Li, X.; Wang, J.-G. Integrating cobalt phosphide and cobalt nitride-embedded nitrogen-rich nanocarbons: High-performance bifunctional electrocatalysts for oxygen reduction and evolution. J. Mater. Chem. A 2016, 4, 10575-10584. [CrossRef]

36. Najam, T.; Ahmad Shah, S.S.; Ding, W.; Ling, Z.; Li, L.; Wei, Z. Electron penetration from metal core to metal species attached skin in nitrogen-doped core-shell catalyst for enhancing oxygen evolution reaction. Electrochim. Acta 2019, 327, 134939. [CrossRef]

37. Gong, K.; Du, F.; Xia, Z.; Durstock, M.; Dai, L. Nitrogen-Doped Carbon Nanotube Arrays with High Electrocatalytic Activity for Oxygen Reduction. Science 2009, 323, 760-764. [CrossRef]

38. Zheng, Y.; Jiao, Y.; Jaroniec, M.; Jin, Y.; Qiao, S.Z. Nanostructured Metal-Free Electrochemical Catalysts for Highly Efficient Oxygen Reduction. Small 2012, 8, 3550-3566. [CrossRef]

39. Yu, D.; Nagelli, E.; Du, F.; Dai, L. Metal-Free Carbon Nanomaterials Become More Active than Metal Catalysts and Last Longer. J. Phys. Chem. Lett. 2010, 1, 2165-2173. [CrossRef]

40. $\mathrm{Hu}, \mathrm{X}$;; $\mathrm{Wu}, \mathrm{Y}$; $\mathrm{Li}, \mathrm{H}$; Z Zhang, Z. Adsorption and Activation of $\mathrm{O}_{2}$ on Nitrogen-Doped Carbon Nanotubes. J. Phys. Chem. C. 2010, 114, 9603-9607. [CrossRef]

41. Najam, T.; Shah, S.S.A.; Ding, W.; Jiang, J.; Jia, L.; Yao, W.; Li, L.; Wei, Z. An Efficient Anti-poisoning Catalyst against SOx, NOx and POx: P, N-Doped Carbon for Oxygen Reduction in Acidic Media. Angew. Chem. Int. Ed. 2018, 57, 15101-15106. [CrossRef] [PubMed]

42. Elmas, S.; Beelders, W.; Pan, X.; Nann, T. Conducting Copper (I/II)-Metallopolymer for the Electrocatalytic Oxygen Reduction Reaction (ORR) with High Kinetic Current Density. Polymers 2018, 10, 1002. [CrossRef] 